\title{
LATEX DERIVED BLENDS OF POLY(VINYL ACETATE) AND NATURAL RUBBER: THERMAL AND MECHANICAL PROPERTIES
}

\author{
Stephen S. Ochigbo ${ }^{1,2}$, Adriaan S. Luyt ${ }^{2}$ and Walter W. Focke ${ }^{1, *}$ \\ ${ }^{1}$ Institute of Applied Materials, Department of Chemical Engineering, University of Pretoria, \\ Pretoria, South Africa \\ ${ }^{2}$ Department of Chemistry, University of the Free State (Qwaqwa Campus), Phuthaditjhaba, \\ South Africa
}

*To whom all correspondence should be addressed, walter.focke@up.ac.za 


\begin{abstract}
Poly(vinyl acetate) (PVAc) and natural rubber blends (NR) were prepared by low shear blending of the corresponding lattices. Thin films were cast using a doctor blade technique. SEM and DMA confirmed the essential immiscibility of the two polymers. Even when the poly(vinyl acetate) forms the matrix phase, it still contains domains encapsulated by a rubber phase where particles that resemble the original latex are visible. This incomplete droplet coalescence of the poly(vinyl acetate) is attributed to the fact that the rubber latex droplets were an order of magnitude smaller than the poly(vinyl acetate) latex droplets. Tensile testing revealed a nonlinear dependence of tensile strength and elongation on blend composition. Surprisingly good tensile yield strengths were obtained at intermediate to high PVAc contents. Thermogravimetric analysis of degradation in air and nitrogen atmospheres indicated independent degradation of the parent polymers.
\end{abstract}

Keywords: Blends; poly(vinyl acetate); poly(isoprene); degradation; mechanical properties; thermal properties 


\section{Introduction}

Polymer blends offer a cost effective route to materials with unique physical properties and processing behavior [1-4]. Prospects for polymer blending have been compared to the alloying of metals. Blend properties are crucially affected by phase morphology and this in turn depends upon a number of factors including the choice of parent polymers, compatibilizers, blend composition, moisture content and the method of blend preparation [5, 6]. Compatibility of the parent polymers is an important issue. Miscible polymers form a homogeneous mixture phase that exhibits the characteristics of a uniform substance [7]. The composition dependence of the physical properties of such blends tends to follow the linear blending rule. However, most polymers are incompatible and undergo phase separation on blending. Unless suitable compatibilizers are employed, poor interfacial adhesion between the individual phases will prevent achievement of mechanical integrity adequate for useful application [1-5]. However, synergistic property improvements are more likely in phaseseparated blend systems.

Poly(vinyl acetate) is a petroleum-derived polymer usually obtained by emulsion polymerization. It features excellent adhesion to various substrates. Thus large quantities of PVAc latex are produced for use as binder in emulsion paints, adhesives and various textilefinishing operations. Some of this material is chemically converted into poly(vinyl alcohol) and poly(vinyl butyral). Owing to its inherent high cold flow, PVAc is of little value in moldings and extrusions [8]. PVAc is rather brittle and rigid but compounding it with other polymers frequently improves physical properties [9-13]. Poly(vinyl acetate) has been blended with various polymers, including poly( $\varepsilon$-caprolactone) and poly(vinyl chloride) [9, 10], poly(L-lactide) [11], poly(styrene) [12], and poly(methyl methacrylate) [13]. Chuu and Meyers [6] previously studied the properties of poly(vinyl acetate)/natural rubber blends. Qiao and Easteal [14] blended PVAc emulsions with 10 or 20 percent natural rubber latex and studied the adhesive performance in wood joints.

Natural rubber (NR) is an agriculturally cultivated renewable resource. It is a classic elastomer that exhibits rubber elasticity. It is, for instance, possible to stretch an elastomer to several times its original length. On removal of tension it snaps back, i.e. it returns almost instantaneously to its original shape and length. Typical elastomers feature excellent abrasion resistance and high toughness. However, NR is essentially poly(cis-isoprene) and the 
presence of double bonds in the chain backbone makes it susceptible to attack by oxygen, especially ozone. The glass transition temperature of rubber is far below ambient temperature and for some applications it is too flexible. Increased stiffness is attained by reinforcement with suitable fillers, e.g. carbon black.

Both PVAc and NR can be obtained in emulsion or "latex" form. Latex blending, as a route to polymer blends, is known but is not widely practiced [14-20]. A unique advantage of latex blends is the fact that the product can be used directly in paints and water-based adhesives. Much commercial exploitation of polymer blending has been connected with the attempt to improve the impact strength of plastics by the inclusion of elastomeric materials [21]. Mixtures of PVAc and NR would fall in this blend category of plastics with elastomers.

This study reports on the utility of latex blending as a route to PVAc-NR blends with improved mechanical properties. Blend morphology and physical properties were investigated by complimentary characterization techniques.

\section{Materials and methods}

\section{Materials}

Poly(vinyl acetate) (PVAc) homopolymer latex (Grade ML50) with a solids content of 52.5 wt. \% and $\mathrm{pH}=6.5$ was obtained from Makeean Polymers, South Africa. This latex was stabilized with ca. 3 wt. \% of a proprietary polyvinyl alcohol dispersant. Natural rubber (NR) latex was supplied by the Rubber Research Institute, Iyanomo, Nigeria. The solids content was 48.0 wt. \%.

\section{Particle size analysis}

The particle size distributions of the lattices were determined on a Malvern Mastersizer Hydro 2000MY instrument.

\section{Latex rheology}

The viscosity of the lattices was measured at $30{ }^{\circ} \mathrm{C}$ on an Anton Paar Physica MCR 301 rheometer fitted with a P-PTD200 Peltier temperature controller. The measurements were done using a $25 \mathrm{~mm}$ parallel plate configuration. Viscosity was measured at shear rates between 5 and $100 \mathrm{~s}^{-1}$. 
Preparation of polymer blends and films

The PVAc latex and NR latex were mixed at ambient temperature using low speed stirring (i.e. a low shear mixing process) to avoid air entrainment. A two-step mixing process was used in order to ensure preparation of homogeneous, non-segregating latex blends. In the first step, the $\mathrm{pH}$ of the NR latex was adjusted to $\mathrm{pH} \approx 10$ by adding ammonia solution. This was necessary to prevent coagulation when blending the rubber latex with the PVAc latex. After pH adjustment, the PVAc latex was gradually added to the NR latex while stirring gently. All blends were prepared by weighing appropriate quantities of the lattices. The natural rubber and poly (vinyl acetate) concentrations were calculated and are reported on dry mass basis. The following mixtures were prepared: 15, 25, 30, 40, 50, 75, 85 and 90 wt. \% PVAc. The density of natural rubber is approximately 0.91 while the density of PVAc is about 1.19. Consequently the corresponding volume \% PVAc in the blends was 11.9, 20.3, 24.7, 33.8, 43.3, 69.6, 81.3 and 87.3 respectively.

Films were cast immediately using a $500 \mu \mathrm{m}$ gauge doctor blade. The substrate was a polyester film (Pelikan Overhead Transparent-Film TF 100 PE) pasted onto a glass sheet. The glass sheets with the wet cast films were immediately transferred into a convection oven set at $50{ }^{\circ} \mathrm{C}$ where they were allowed to dry for 18 hours. This temperature is well in excess of the stated value of $20^{\circ} \mathrm{C}$ for the minimum film-forming temperature (MFFT), also called the "white point" [22] for the poly(vinyl acetate) latex. With this procedure homogeneous films were obtained, i.e. no segregation of the lattices was discernable from visual inspection.

After the drying period, the glass sheets were removed from the oven and allowed to cool down to ambient conditions. The polyester sheets, now containing the dry films, were removed from the glass sheets. They were removed from the polyester substrate after cooling with liquid nitrogen. This reduced the adhesion between the two films allowing the cast sheet to be peeled off freely. The thicknesses of the free films were measured using an electronic vernier caliper. They ranged from 155 to $290 \mu \mathrm{m}$.

\section{Scanning electron microscopy (SEM)}

Film specimens were cryogenically fractured using liquid nitrogen. The samples were mounted, with the fractured ends pointing vertically up, on an adhesive-activated stub using quick-drying conductive carbon paint (Colloidal Graphite in Isopropanol-20\% solids, SPI 
Supplies Division of Structure Probe, USA). The specimens were stained with osmium tetroxide $\left(\mathrm{OsO}_{4}\right)$ before examination with a scanning electron microscope (JEOL JSM-840, Japan).

Thermogravimetric analysis

Thermogravimetric analyses in an air atmosphere were performed using a Mettler Toledo TGA/SDTA $851^{\mathrm{e}}$ instrument. Samples ( $\pm 15 \mathrm{mg}$ ) were placed in $70 \mu \mathrm{l}$ alumina crucibles. The heating rate was set at $10{ }^{\circ} \mathrm{C} \cdot \mathrm{min}^{-1}$ and the gas flow rate at $50 \mathrm{ml} \cdot \mathrm{min}^{-1}$. The temperature range was 25 to $600{ }^{\circ} \mathrm{C}$. Thermal pyrolysis studies were performed on a Perkin-Elmer TAC 7/DX thermal analyzer. Samples ( $\pm 8 \mathrm{mg}$ ) were heated at a scan rate of $10{ }^{\circ} \mathrm{C} \cdot \mathrm{min}^{-1}$ from 30 to $600{ }^{\circ} \mathrm{C}$ in an inert nitrogen atmosphere at a constant gas flow rate of $40 \mathrm{ml} \cdot \mathrm{min}^{-1}$.

Dynamic mechanical analysis (DMA)

Rectangular film strips measuring $50 \mathrm{~mm} \times 12 \mathrm{~mm}$ were cut. Dynamic mechanical analysis (DMA) was performed on a Perkin Elmer Diamond DMA using the 3-point bending mode and a frequency of $1 \mathrm{~Hz}$. The strain amplitude was set at $20 \mu \mathrm{m}$ with initial force amplitude of $100 \mathrm{mN}$. The sample was heated in an inert atmosphere from -70 to $70{ }^{\circ} \mathrm{C}$ at a temperature scan rate of $5{ }^{\circ} \mathrm{C} \cdot \mathrm{min}^{-1}$. It was found that the moduli values (in the glassy regions) measured by samples clamped at ca. $-70{ }^{\circ} \mathrm{C}$ were about an order of magnitude lower than those measured with the samples clamped taught at room temperature. However, when clamped in this way no measurements were possible at the higher temperatures as thermal expansion effects caused the films to become too floppy. The purpose of the DMA measurements was to probe the nature of the blends phase behavior rather than generating accurate modulus values. It was therefore decided to use the data obtained with the samples clamped taught in position at room temperature. They are reported here as apparent moduli scaled by a factor of one tenth in order to reflect realistic magnitudes.

Mechanical properties 
Dumb-bell shaped test specimens with a gauge width of $5.08 \mathrm{~mm}$ were obtained using a punch. Tensile properties were determined using a Hounsfield Model H5KS tensile tester at $50 \mathrm{~mm} \cdot \mathrm{min}^{-1}$ crosshead speed at ambient temperature $\left(22{ }^{\circ} \mathrm{C}\right)$ in accordance to test method ASTM D632-882. The results of at least five samples were obtained and reported as averaged values.

\section{Results and discussion}

\section{Latex properties}

Figure 1 shows the cumulative particle distributions for the two lattices. The median particle sizes were determined as $4.5 \mu \mathrm{m}$ and $0.34 \mu \mathrm{m}$ for poly(vinyl acetate) and natural rubber lattices respectively. Figure 1 also reveals that the former latex has a narrower particle size distribution than the latter.

Figure 2 summarizes the viscosity data measured at different shear rates. The neat lattices as well as their blends show shear thinning non-Newtonian rheological behavior. Farris [23] showed that blending of suspensions containing spherical particles with different diameters should lead to a reduced viscosity. However, in the present case the viscosities of the latex blends exceed the values predicted by the linear blending rule. This is attributed to interactions between dissimilar emulsion particles that are stronger than those between particles of similar type. Such preferred interactions also help to maintain the well-mixed state of the homogeneous dispersion as it prevents gravity driven segregation.

\section{Morphology}

Figures 3a \& b and 3c show SEM pictures of the fracture surfaces of a film containing $40 \mathrm{wt}$. $\%$ and 75 wt. \% poly(vinyl acetate) respectively. Figure 3a gives an edge-on view and reveals a homogeneous distribution of the phases across the thickness of the film. Figure $3 b$ of the fracture surface, reveals more or less spherical inclusions that constitute poly(vinyl acetate) phase domains dispersed in the natural rubber matrix. These particles are similar in size (2 - 3 $\mu \mathrm{m}$ ) to the particles in the poly(vinyl acetate) parent latex. This implies that the domain size, of the dispersed phase, is determined primarily by the dimensions of the original emulsion droplets. This is not unexpected in view of the immiscibility of the polymers present, the higher consistency of the PVAc, the low shear mixing method that was employed and the fact that, volumetrically, the PVAc is the minor phase. 
The highly irregular fracture surface seen in Figure 3c points towards a complex morphology for the blend containing $75 \mathrm{wt} \%$ poly(vinyl acetate). In this sample the poly(vinyl acetate) is volumetrically the major phase and it should form the continuous matrix phase. However, particles originating from the parent PVAc lattices are clearly discernable. The observed morphological structure suggests imperfect emulsion droplet coalescence of the majority phase (PVAc) at the microscopic level. While SEM reveals a complicated phase structure, DMA results suggest that the material behavior is nevertheless chiefly determined by the properties of the PVAc phase. Note the distinct boundary structures. Some were probably formed around a single droplet whereas others appear to have formed around larger phase domains containing remnants of several PVAc droplets. The incomplete coalescence of the majority phase emulsion droplets can be attributed to a geometric effect. At this composition the minor phase is derived from much smaller droplets. They are able to coat the larger droplets of the major PVAc phase forming a layer around them. In this way some of them may become isolated from other droplets and fail to merge with them to form part of the continuous major phase. This means that the observed boundary layer structures probably represent a rubber phase formed by the coalescence of the much smaller rubber particles around the much larger PVAc droplets. Figure 4 schematically illustrates (in two dimensions) the isolation of a large droplet by a swarm of smaller particles aggregating at its surface.

\section{Dynamic mechanical analysis}

Figure 5 shows the storage modulus of NR, PVAc and two blends as a function of temperature. The curves for the neat lattices show sharp decreases, by approximately three orders of magnitude, in modulus at the corresponding glass transition temperatures for NR (Tg $\approx-55^{\circ} \mathrm{C}$ ) and PVAc ( $\mathrm{Tg} \approx 25^{\circ} \mathrm{C}$ ) [24]. The curves for the blends show intermediate behavior. The storage modulus for 25 wt \%, 40 wt \% and 60 wt \% PVAc show distinct stepwise reductions in modulus. The first drop occurs at a temperature similar to that for the natural rubber implying that the PVAc is not miscible with NR. The second drop occurs at intermediate temperatures suggesting that the modulus of the PVAc phase is modified by the presence of NR. This conjecture is supported by the composition dependence of the relative change in modulus at each step. Even at $40 \mathrm{wt} \%$ PVAc, the second higher temperature step is already greater in magnitude than the first step change in modulus. As the concentration of PVAc rises beyond $60 \mathrm{wt} \%$, the modulus versus temperature curves rapidly approach that of 
the neat PVAc. This indicates a continuous poly(vinyl acetate) matrix phase for compositions containing $60 \mathrm{wt} \%$ (i.e. $53 \mathrm{vol} \%$ ) or more PVAc.

Figure 6 shows the variation of the loss modulus of NR, PVAc and selected blends as a function of temperature. Both pure rubber and pure PVAc show peaks near their known glass transition temperatures, i.e. the peak in the loss modulus can be identified with the glass transition temperature. Although the data shows some scatter, the peak position associated with the Tg of rubber, appears to remain at roughly the same temperature, irrespective of the PVAc content of the blends. However, the peak corresponding to the Tg of the poly(vinyl acetate) appears to shift towards higher temperatures with increase in rubber content. This behavior is known as antiplasticization [25].

Thermogravimetric analysis (TGA)

Figures 7 and 8 show that the TGA results obtained in nitrogen and air are similar. The main difference between the results is a slight shift towards lower degradation temperatures in air (see Figure 8). However, the poly(vinyl acetate) is less affected by the nature of the atmosphere than the natural rubber. Figure 7 shows that all the samples retained more than $95 \%$ mass below $280^{\circ} \mathrm{C}$.

The neat PVAc shows a two-stage degradation process, which is consistent with literature reports [26]. In the first stage de-acetylation occurs and conjugated double bonds are formed along the polymer backbone. In the second stage, structural degradation of the polymer proceeds leading to the evolution of aromatic compounds. The NR degradation shows up as a single stage in the TGA. The degradation profiles of the blends are roughly in proportion to the parent polymers if a slight shift to lower temperatures is disregarded. Thus the degradation pathways of the individual polymers are almost unaffected by the presence of the other polymer.

Tensile properties

Typical stress-strain curves for different compositions are shown in Figure 9. The shape of the curves for compositions containing less than $50 \mathrm{wt} \%$ poly(vinyl acetate) showed the conventional response expected for elastomers. Films containing higher levels of PVAc show stress-strain behavior more akin to a typical thermoplastic, e.g. low density polyethylene. A key feature of these compositions is that they exhibit a definite yield point. For the 50 wt \% 
PVAc blend, the yield point is vestigial. As the PVAc content increases, the yield point rapidly becomes well developed. A well defined yield point is observed for the neat PVAc film. The stress attains a local maximum value at the yield point. It then drops to a lower plateau value as the sample undergoes necking before slowly rising again to the ultimate breaking stress at an elongation exceeding $200 \%$. For the compositions containing 60, 75 and $85 \mathrm{wt} \%$ PVAc, the maximum stress actually coincides with the yield point value. In fact, the latter two compositions show yield stress values that exceed the maximum tensile stress recorded for the neat poly(vinyl acetate).

Figure 10 shows the effect of PVAc content on the tensile strength and elongation-at-break. The elongation-at-break is high (> 400\%) for the NR sample. It shows a concave concentration dependence reaching a minimum at ca. 60 wt \% PVAc. The tensile strength increases exponentially with PVAc content up to $80 \mathrm{wt} \%$ PVAc. The blends with composition close to this value actually feature better tensile strengths than the parent polymers. The precise reason for this synergistic behavior is not presently understood but is likely associated with the observed antiplasticization and the complex phase morphology obtained at these compositions.

\section{Conclusions}

Blends of poly(vinyl acetate) and natural rubber in the form of thin sheets were prepared by casting emulsion mixtures followed by drying at $50{ }^{\circ} \mathrm{C}$. The film poperties were investigated by scanning electron microscopy, thermal analysis and tensile testing. SEM studies revealed the presence of phase domain structures reminiscent of the original size and shape of the poly(vinyl acetate) emulsion droplets. Samples containing PVAc as major phase show a complex morphology. This is ascribed to the effect of an order of magnitude difference in the emulsion droplet sizes. Adding up to 85 wt. \% PVAc improved tensile strength albeit with a concomitant loss in elongation to break. To a first approximation, thermal degradation in air and nitrogen atmospheres was consistent with the independent degradation of the constituent polymers.

\section{Acknowledgment}


Financial support for this research from the Institutional Research Development Programme (IRDP) of the National Research Foundation (NRF), the University of the Free State and the University of Pretoria is gratefully acknowledged. 


\section{References}

1. Paul DR, Sperling LH (1986) Adv Chem Ser 211:1

2. Gesner BD (1967) Polym Prepr (Am Chem Soc, Div Polym Chem) 8: 1482

3. Bergen Jr. RL (1967) Polym Prepr (Am Chem Soc, Div Polym Chem) 8: 1473

4. Utracki LA, Weiss RA (1989) Multiphase Polymers, ACS Symp Ser 195:1

5. Dyson RW (1990), Engineering Polymers, Chapman and Hall, New York, pp 20-28

6. $\quad$ Chuu MS, Meyers RR (1987) J Appl Polym Sci 34:1447

7. $\quad$ Singh YP, Singh RP (1983) Eur Polym J 19: 529

8. Brydson JA (1975) Plastics materials, $3^{\text {rd }}$ ed., Newnes-Butterworths, London, pp 317321

9. Sivalingam G, Karthik R, Madras G (2004) Polym Degrad Stabil 84:345

10. Sivalingam G, Karthik R, Madras G (2004) J Appl Polym Sci 93:1378

11. Gajria AM, Dave V, Gross RA, McCarthy SP (1996) Polymer 37:437

12. Mamza PAAP, Folaranmi FM (1996) Eur Polym J 32:909

13. Haiyang Y, Pingping Z, Feng R, Yuanyuan W, Tiao Z (2000) Eur Polym J 36:21

14. Qiao L, Easteal AJ (2001) Pigment and Resin Technology 30: 79

15. Vidovska D, Maurer FHJ (2006) Compos Interfaces 13: 819

16. Winnik MA, Feng J (1996) J Coat Technol 68: 39

17. Feng J, Winnik MA, Shivers RR, Clubb B (1995) Macromolecules, 28: 7671

18. Lepizzera S, Lhommeau C, Dilger G, Pith T, Lambla M (1997) J Polym Sci, Part B: Polym Phys 35: 2093

19. Robeson LM, Vratsanos MS (2000) Macromol Symp 155: 117

20. Peng Z, Kong LX, Li S-D, Chen Y, Huang MF (2007) Compos Sci Technol 67: 3130

21. Ibrahim A, Dahlan M (1998) Prog Polym Sci 23: 665

22. Pizzi A (1983) Wood adhesives - chemistry and technology, Marcel Dekker, New York, p 328

23. Farris RJ (1968) Trans Soc Rheol 12: 281

24. Brandrup J, Immergut EH (1989), Polymer handbook, $3^{\text {rd }}$ ed., Wiley, New York, V/7

25. Young RJ (1981) Introduction to polymers, Chapman and Hall, London, pp 206-207

26. Sivalingam G, Karthik R, Madras G (2003) Ind Eng Chem Res 42:3647 


\section{Figure captions}

Figure 1 Cumulative particle size distributions for the neat poly(vinyl acetate) latex and natural rubber latex.

Figure 2 The effect of shear rate on the viscosities of the poly(vinyl acetate) latex, the natural rubber latex and some of their blends measured at shear between 5 and $100 \mathrm{~s}^{-1}$.

Figure 3 SEM images of the fracture surfaces of the latex blends containing (a) \& (b) 40 wt \% and (c) 75 wt \% poly(vinyl acetate). Spherical particles are clearly visible in each micrograph but in the latter case the morphology appears to more complex than just a dispersion of rubber particles in a poly(vinyl acetate) matrix.

Figure 4 Schematic illustration of the isolation of PVAC droplets by swarms of the much smaller rubber droplets.

Figure 5 Storage modulus vs. temperature curves measured at $1 \mathrm{~Hz}$ of samples containing different amounts of PVAc.

Figure 6 Loss modulus vs. temperature curves measured at $1 \mathrm{~Hz}$ of samples containing different amounts of PVAc. To aid visualization the curves were shifted up by using the multiplier shown in brackets.

Figure 7 TGA curves obtained in a nitrogen atmosphere showing the effect of blend composition.

Figure 8 TGA curves obtained in an air atmosphere showing the effect of blend composition.

Figure 9 Stress-strain curves of samples containing different amounts of PVAc.

Figure 10 Dependence of tensile strength and elongation-at-break on PVAc content. 
Figure 1 Cumulative particle size distributions for the neat poly(vinyl acetate) latex and natural rubber latex.

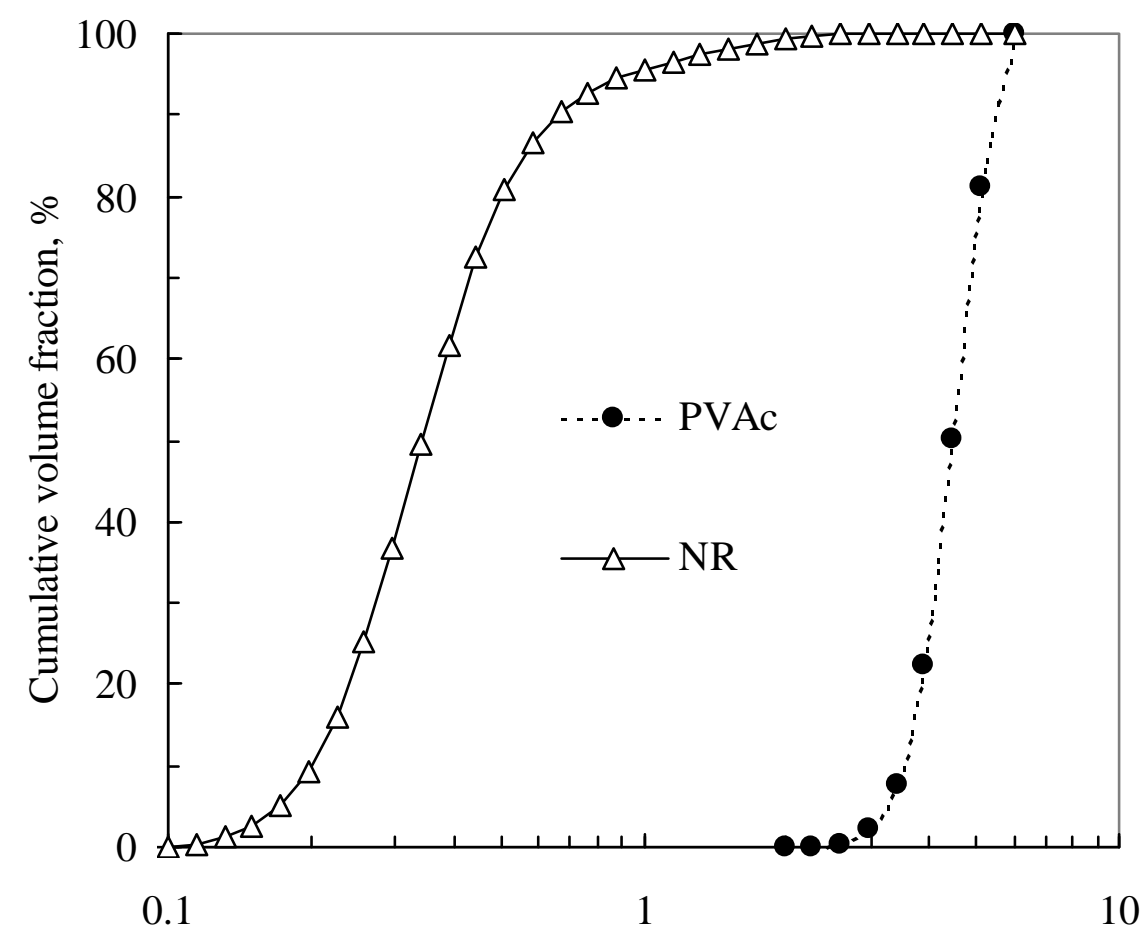

Diameter, $\mu \mathrm{m}$ 
Figure 2 The effect of shear rate on the viscosities of the poly(vinyl acetate) latex, the natural rubber latex and some of their blends measured at shear between 5 and $100 \mathrm{~s}^{-1}$.

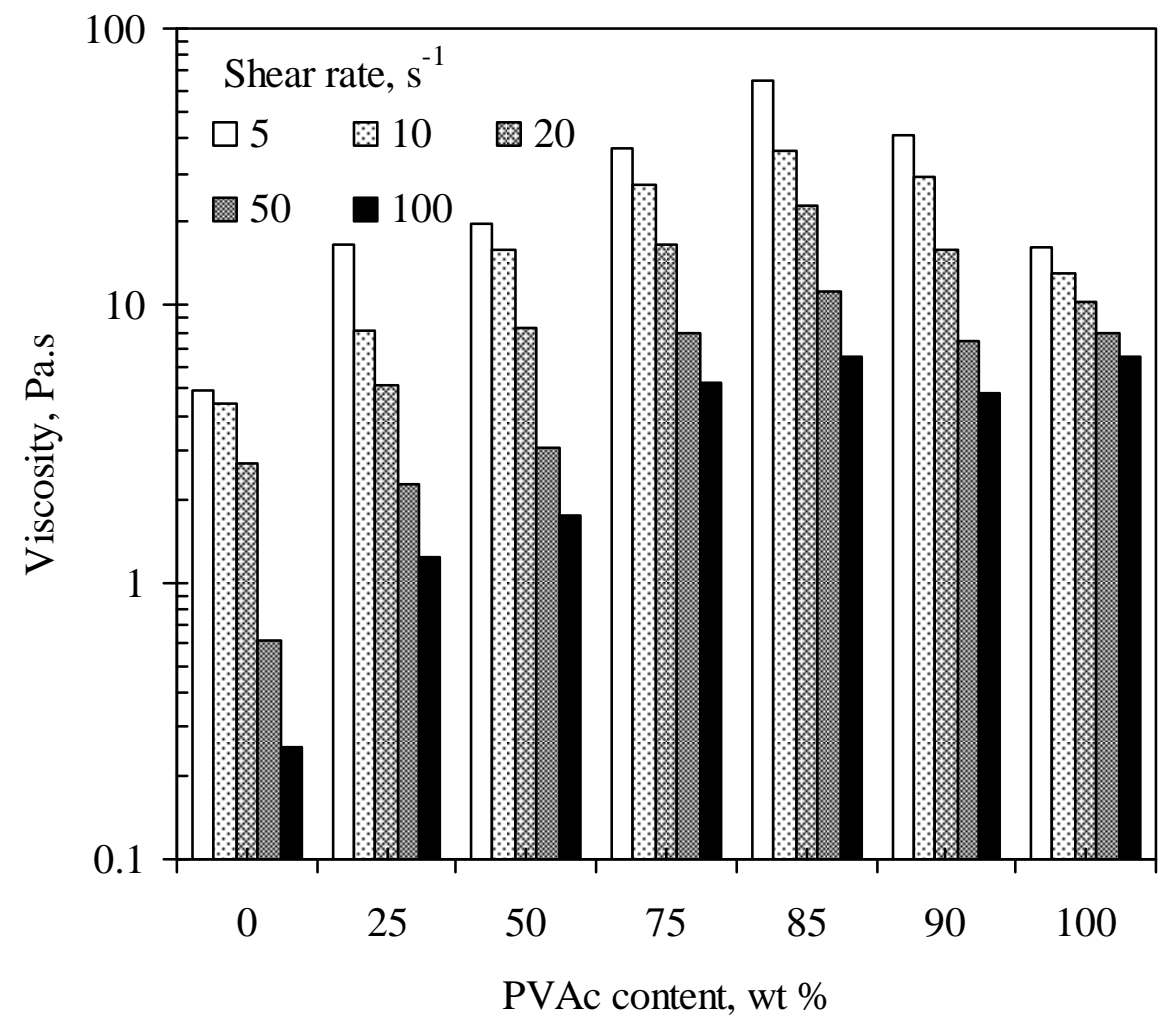


Figure 3 SEM images of the fracture surfaces of the latex blends containing (a) \& (b) 40 wt \% and (c) 75 wt \% poly(vinyl acetate). Spherical particles are clearly visible in each micrograph but in the latter case the morphology appears to more complex than just a dispersion of rubber particles in a poly(vinyl acetate) matrix. 


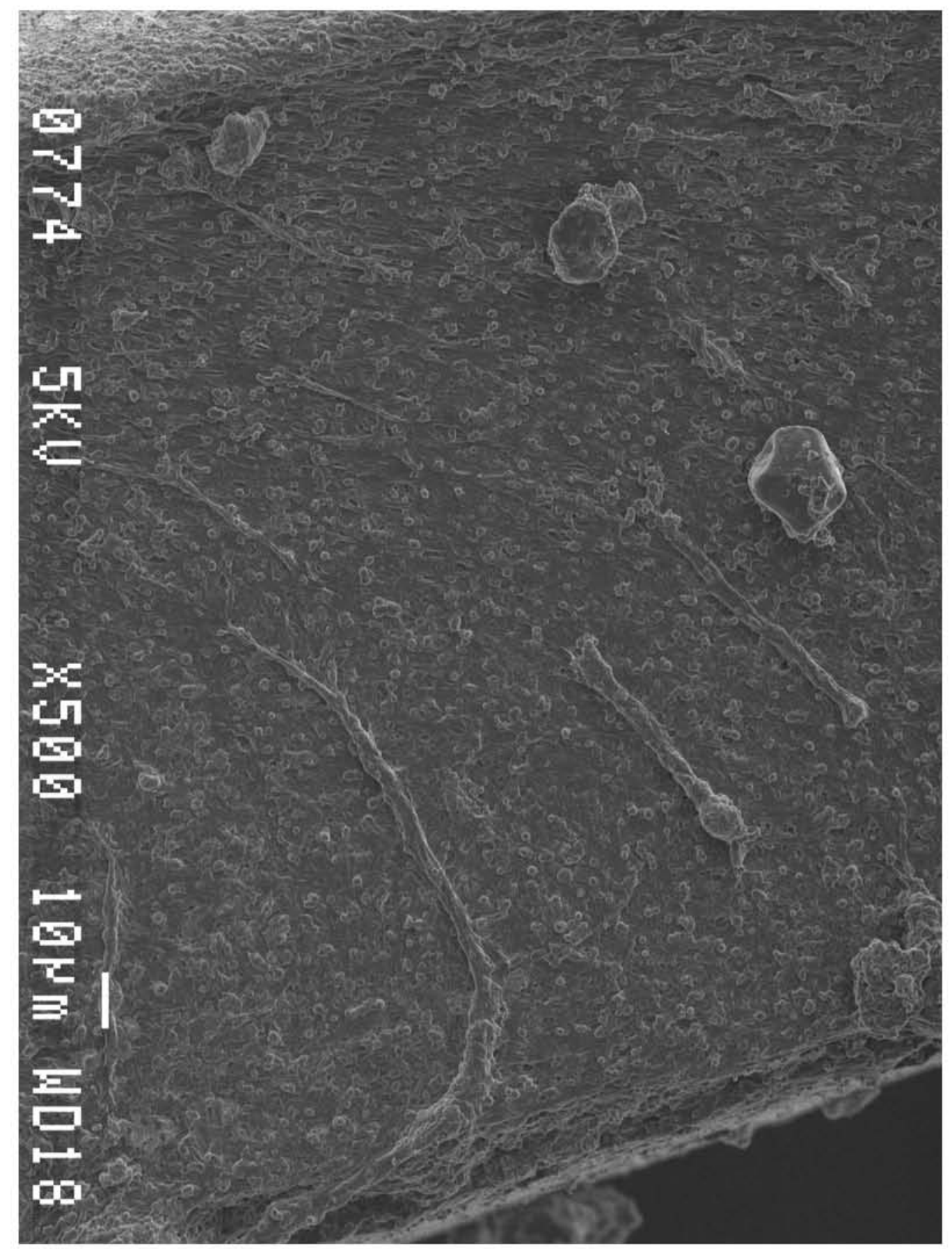

3(a) 


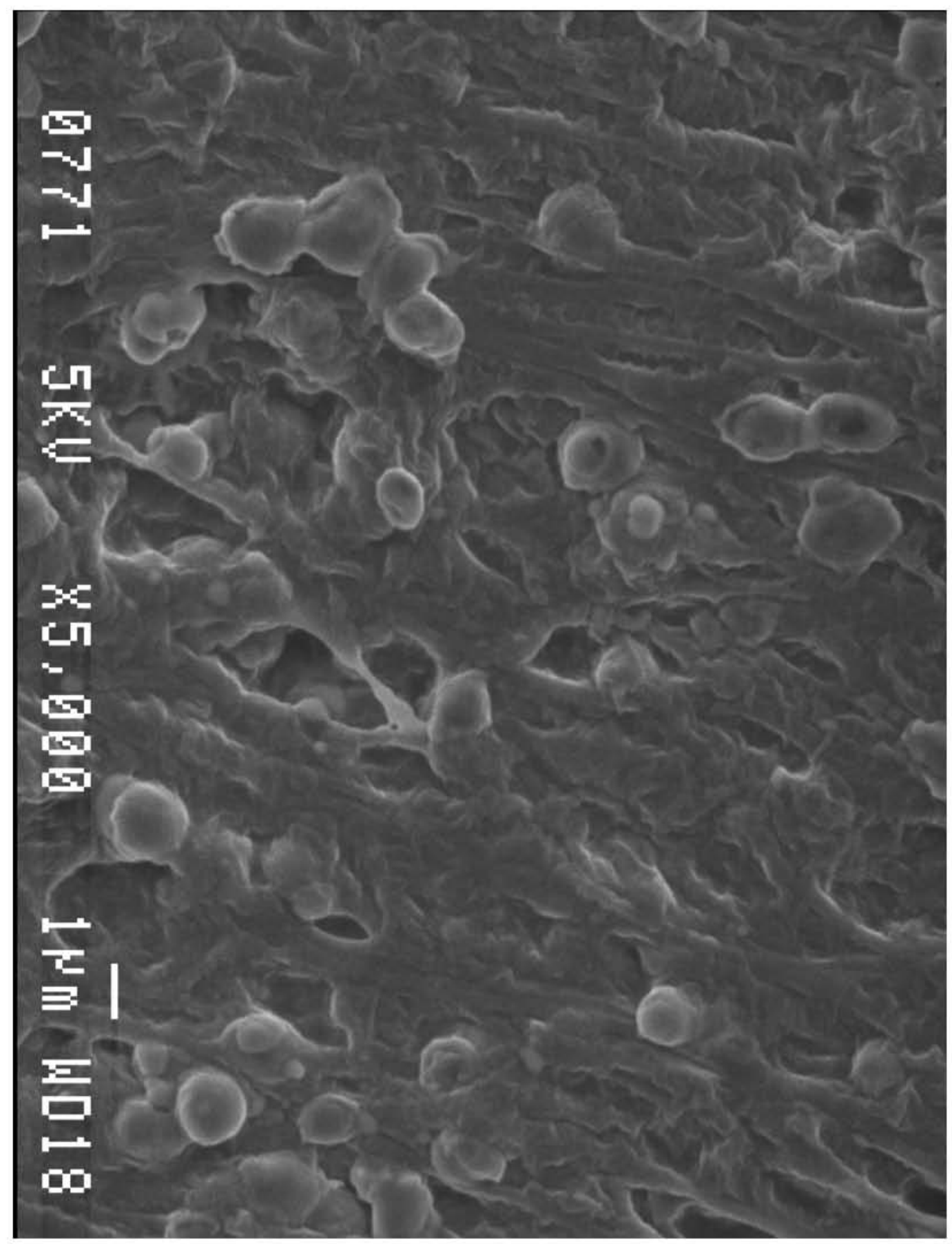

3(b) 


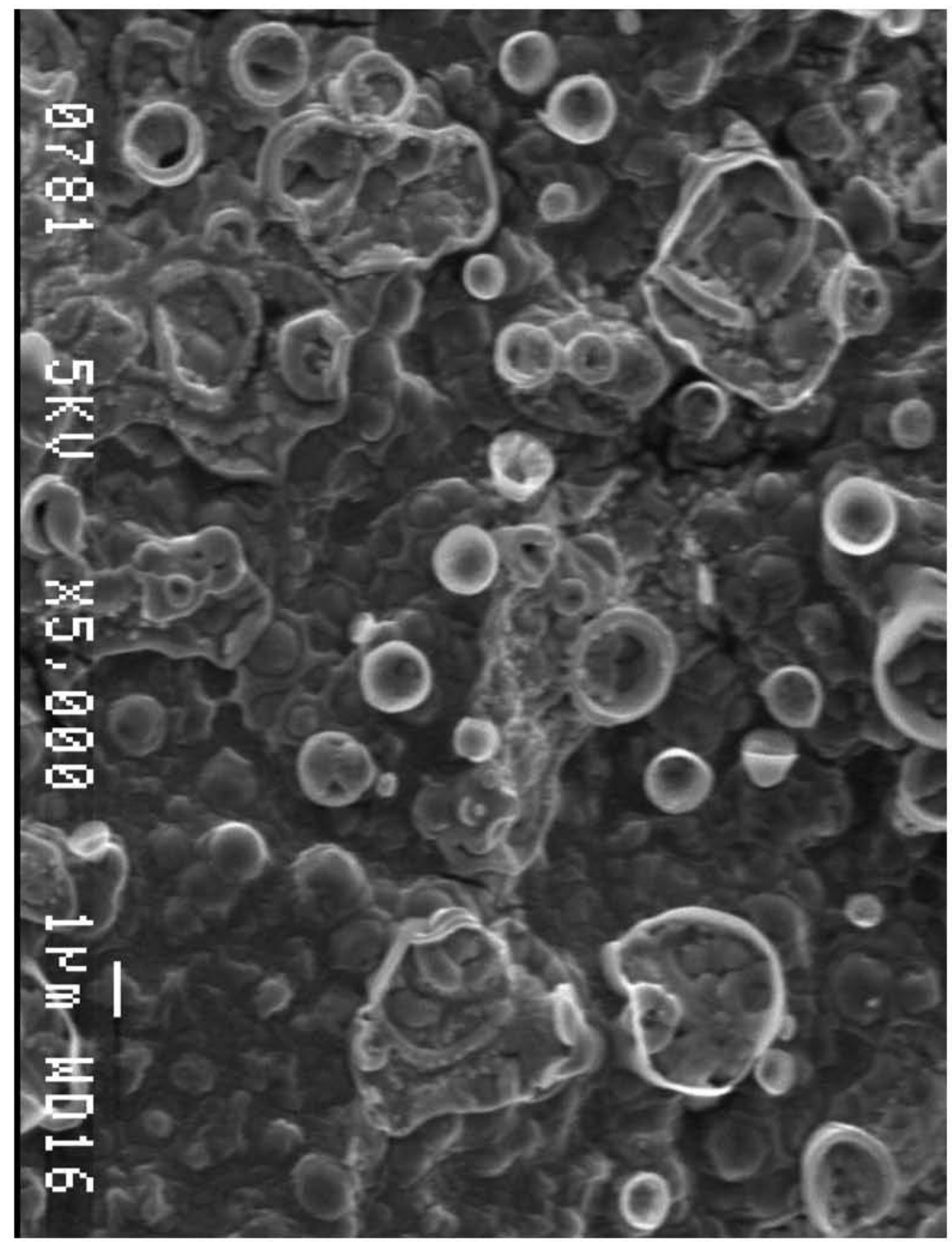

3(c)

Figure 4 Schematic illustration of the isolation of PVAC droplets by swarms of the much smaller rubber droplets. 


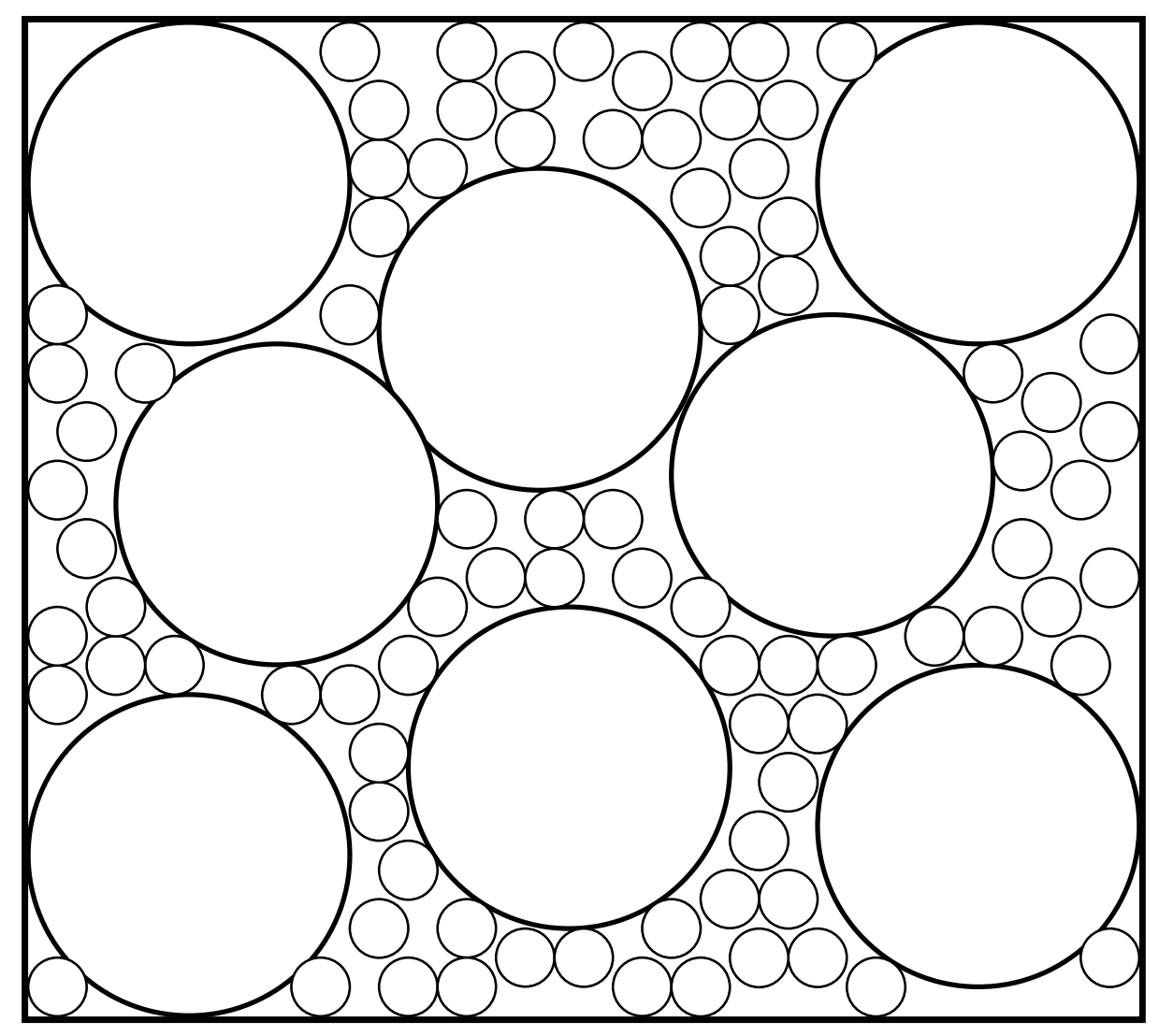

Figure 5 Storage modulus vs. temperature curves measured at $1 \mathrm{~Hz}$ of samples containing different amounts of PVAc. 


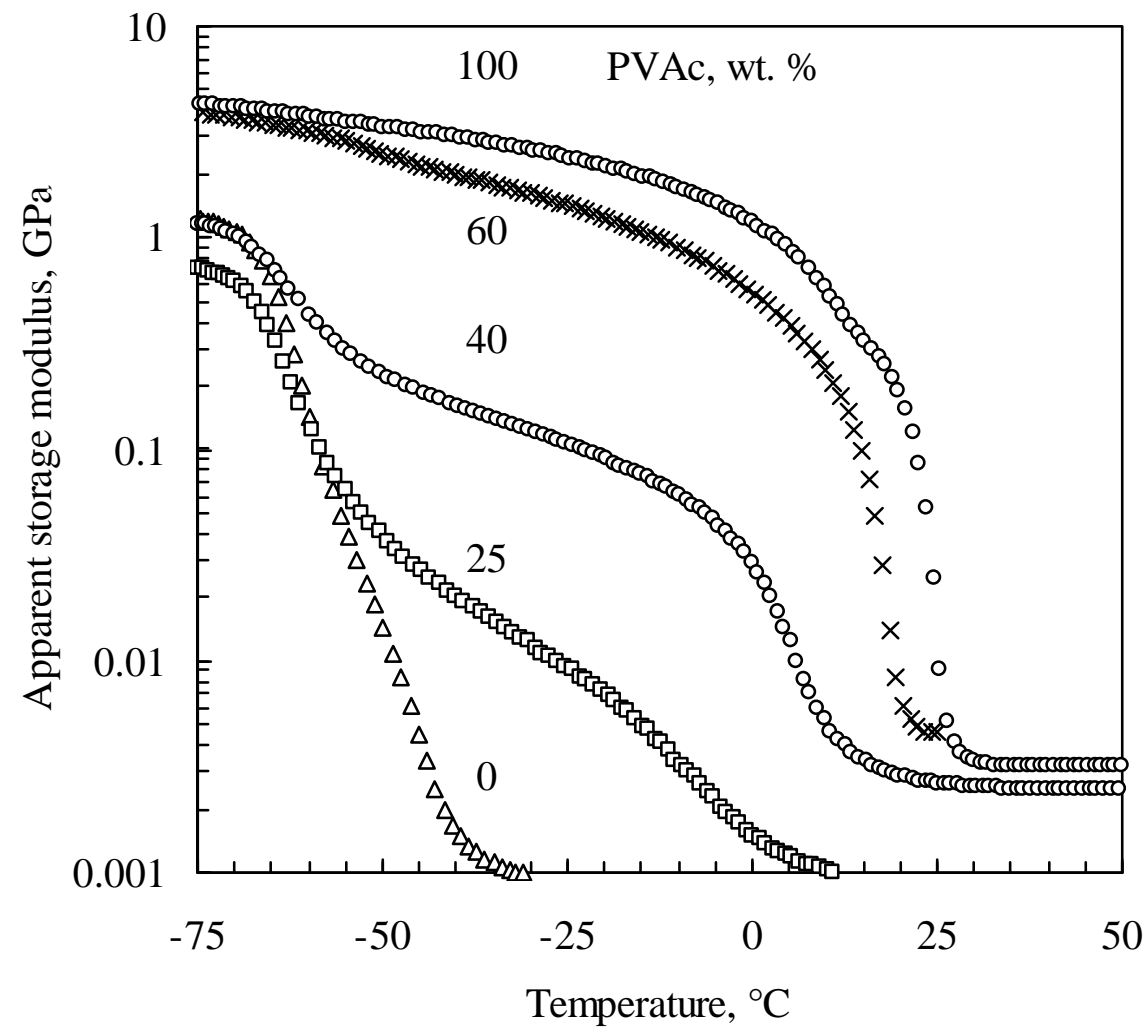


Figure 6 Loss modulus vs. temperature curves measured at $1 \mathrm{~Hz}$ of samples containing different amounts of PVAc. To aid visualization the curves were shifted up by using the multiplier shown in brackets.

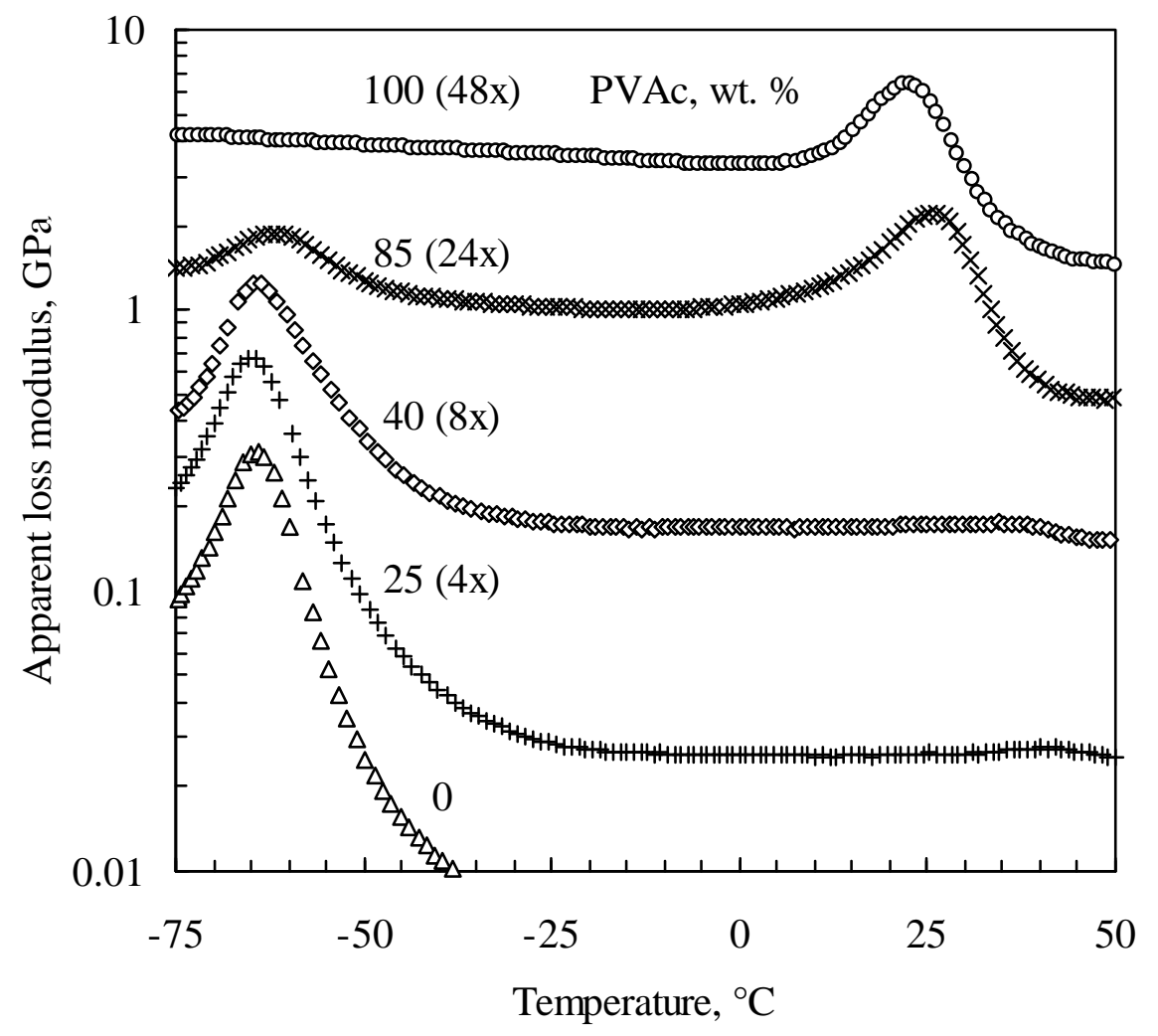


Figure 7 TGA curves obtained in a nitrogen atmosphere showing the effect of blend composition.

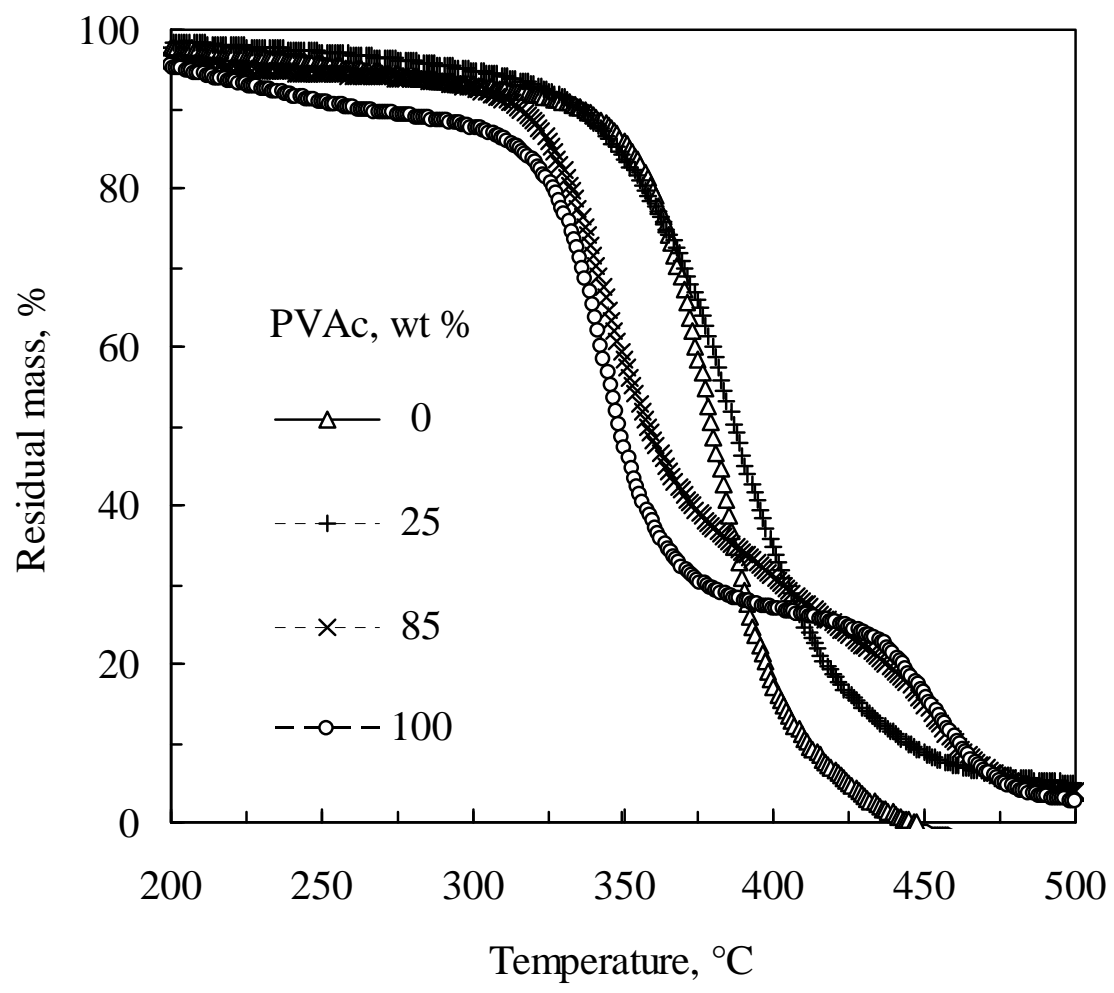


Figure 8 TGA curves obtained in an air atmosphere showing the effect of blend composition.

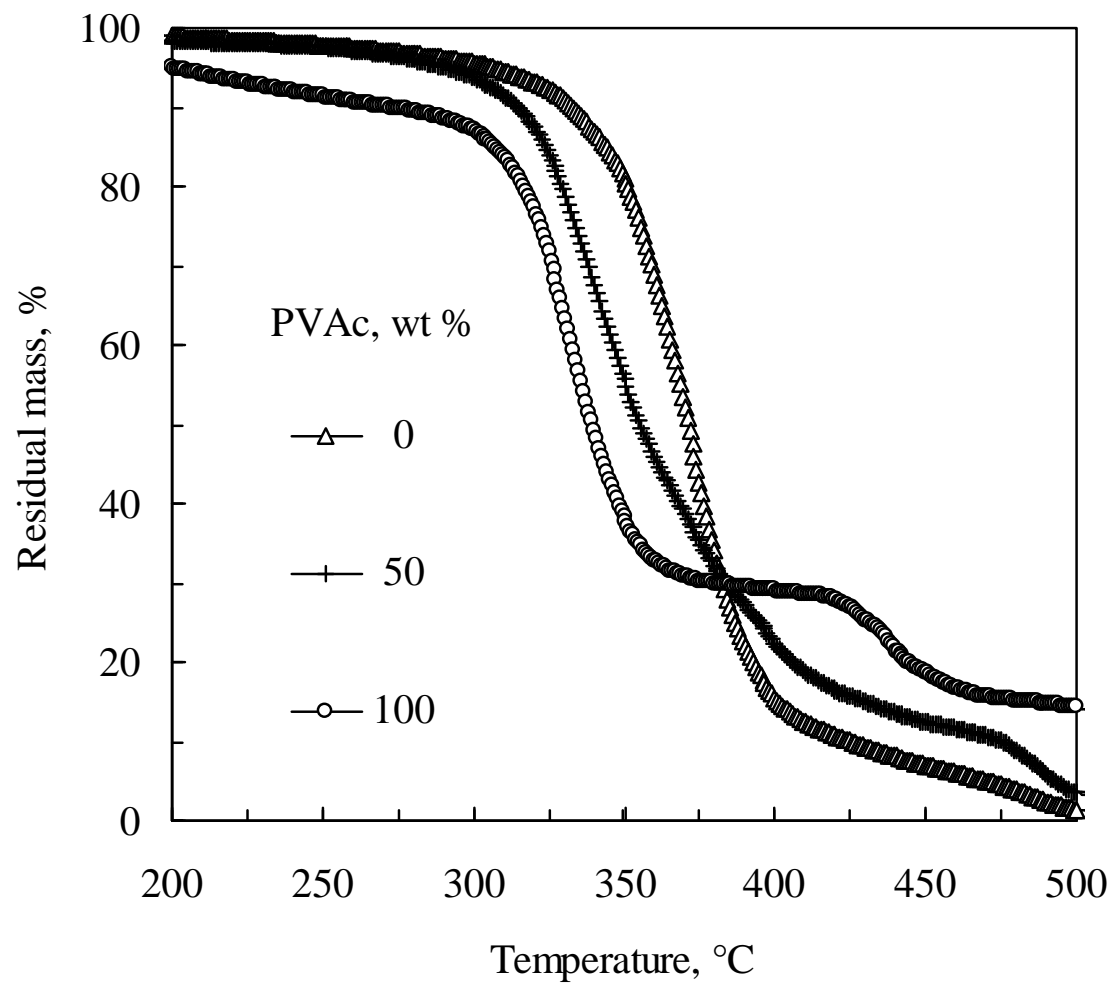

Figure 9 Stress-strain curves of samples containing different amounts of PVAc. 


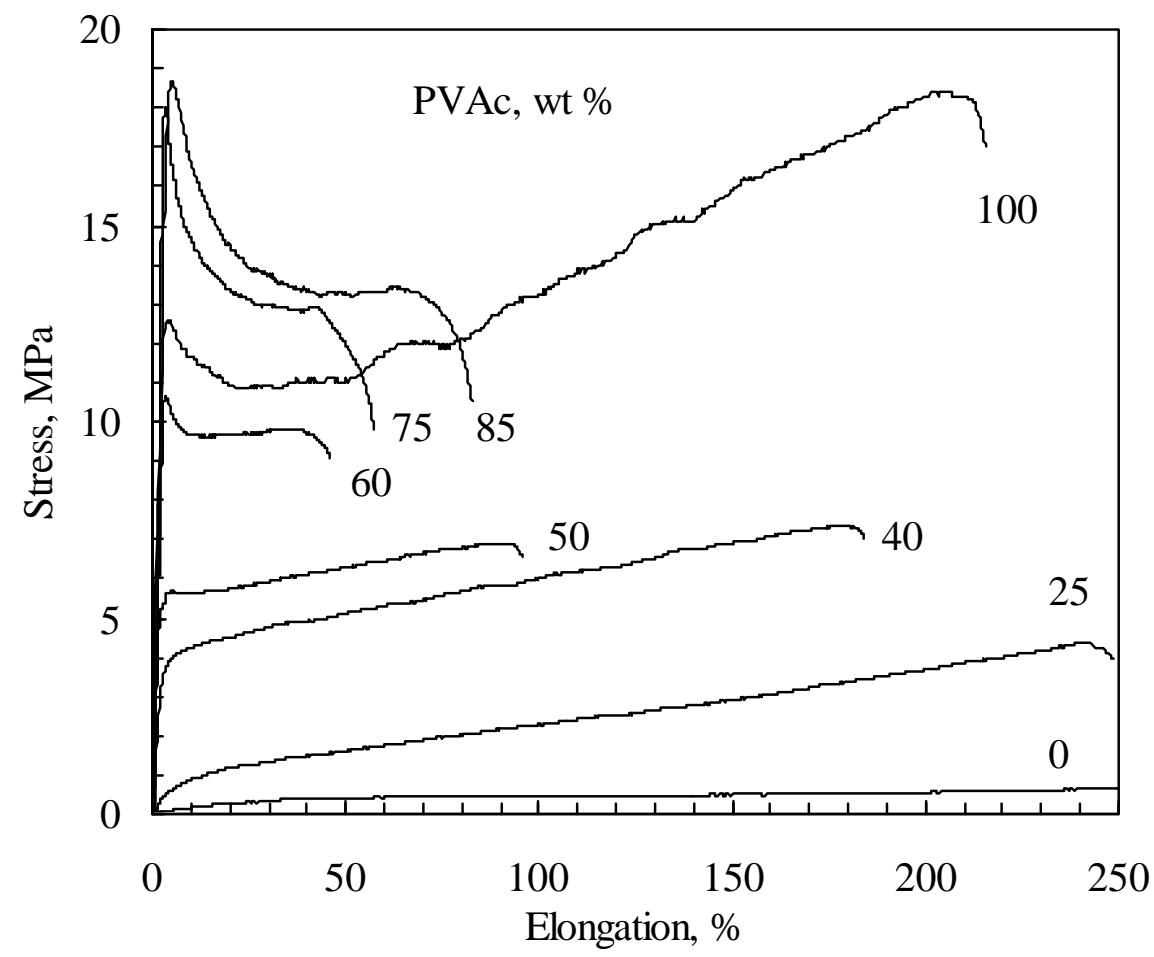

Figure 10 Dependence of tensile strength and elongation-at-break on PVAc content. 


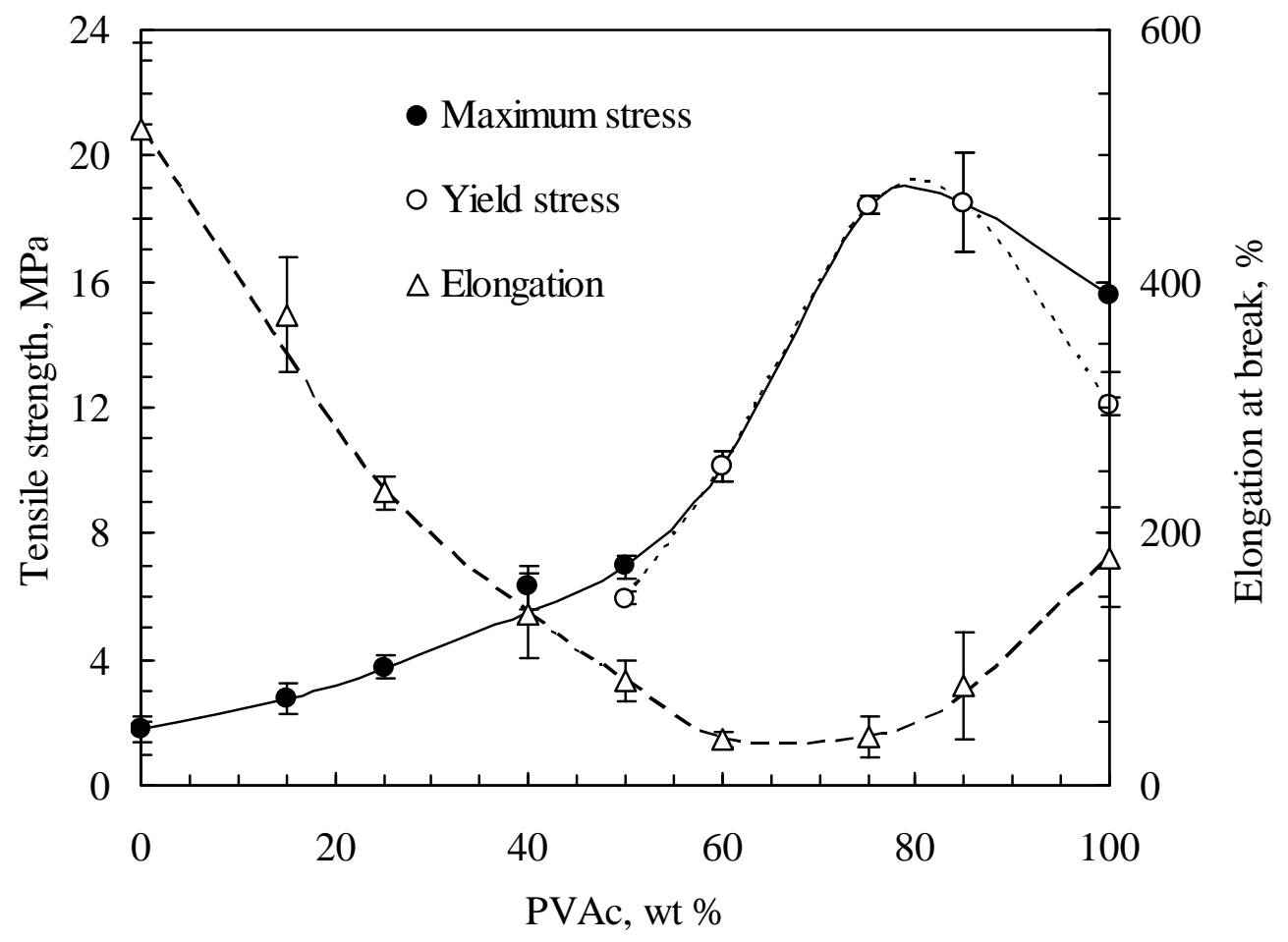

